Article

\title{
Peripheral Heat Transfer Coefficient during Flow Boiling: Comparison between 2-D and 1-D Data Reduction and Discussion about Their Applicability
}

\author{
Rita Mastrullo and Alfonso William Mauro * \\ Department of Industrial Engineering, Università degli studi di Napoli-Federico II, P. le Tecchio-80, \\ 80125 Naples, Italy; rita.mastrullo@unina.it \\ * Correspondence: wmauro@unina.it
}

Received: 11 October 2019; Accepted: 22 November 2019; Published: 25 November 2019

\begin{abstract}
This paper presents a critical analysis of possible data reduction procedures for the evaluation of local heat transfer coefficient during flow boiling experiments. The benchmark method using one-dimensional (1-D) heat transfer in a heated tube was compared to a new data reduction method in which both radial and circumferential contributions to the conductive heat transfer inside a metal tube are considered. Using published experimental flow boiling data, the circumferential profiles of the wall superheat, inner wall heat flux, and heat transfer coefficients were independently calculated with the two data reduction procedures. The differences between the two methods were then examined according to the different heat transfer behavior observed (symmetric or asymmetric), which in turn was related to the two-phase flow regimes occurring in a channel during evaporation. A statistical analysis using the mean absolute percentage error (MAPE) index was then performed for a database of 417 collected flow boiling data taken under different operating conditions in terms of working fluid, saturation temperature, mass velocity, vapor quality, and imposed heat flux. Results showed that the maximum deviations between the two methods could reach up to $130 \%$ in the case of asymmetric heat transfer. Finally, the possible uses of the two data reduction methods are discussed, pointing out that the two-dimensional (2-D) model is the most reliable method to be employed in the case of high-level modeling of two-phase flow or advanced design of heat exchangers and heat spreader systems.
\end{abstract}

Keywords: data reduction; flow boiling; 2-D heat transfer; heat transfer coefficient

\section{Introduction}

Refrigeration and air conditioning are both receiving particular attention nowadays, with the two fields being under the strict control of several ongoing policies and regulations concerning the environment. In fact, it has been estimated that, for a typical European household, about $30 \%$ of the total energy consumption is required for refrigeration and air conditioning purposes [1]. This share is almost double that for the commercial sector [2]. Furthermore, the European Union's regulations on fluorinated gases, known as the EU F-Gas Regulation [3], pushes toward a consistent reduction of greenhouse gas emissions and promotes the utilization of eco-friendly refrigerants.

In this dynamic context, the correct design of heat exchangers (i.e., evaporators) is the key factor for fair estimation and optimization of system performance [4]. This requires dedicated, reliable experiments to obtain more, new high-quality two-phase heat transfer data. By following this approach, it is then possible to develop new heat transfer prediction methods or modify the existing ones, which are mostly calibrated on conventional fluids and may not be sufficiently precise when used outside the operating conditions on which they have been based $[5,6]$. 
A comprehensive amount of scientific research has already been carried out to investigate the boiling performance of new low-global warming potential (GWP) refrigerants by testing a wide range of fluids [7-11], tube geometries [12], channel orientations [13], and operating conditions [14]. In these works, different data analysis methods were independently proposed according to, for instance, the measurement instrumentation at disposal and the tube heating method. In all cases, there was a continuous effort aimed at increasing the accuracy of flow boiling heat transfer data using more accurate measurement instrumentation devices and improving the experimental method.

Conventionally, the data reduction procedure employed for the estimation of heat transfer coefficient is of the one-dimensional (1-D) type, meaning that one-dimensional heat transfer inside a heated metal tube is considered. In a few cases, more complex devices, such as infrared thermographic cameras [15], are used, even if they require an elaborate procedure for calibration. When the outer wall temperature is obtained [16], the 1-D heat transfer inside the channel is still the main hypothesis considered. The benchmark 1-D data reduction has the advantage of being a solid approach that is very easy to implement. In addition, for heat exchanger design purposes, the correlations developed with the 1-D method can be used in reverse by employing it back from the heat transfer coefficient to get the wall heat flux with fair reliability if the same hypotheses are considered.

However, a sharper local definition of the heat transfer coefficient is often required in the case of heat spreader systems for cooling of electronic devices as local hot spots may contribute to malfunctioning and burnout. Several studies aimed at modeling the entire flow motion and the heat transfer phenomenon have used measurement of the local film thickness [17] to find its relationship with the heat transfer coefficient. One such example is the study by Mauro et al. [18], which looked at asymmetric annular flow in a single tube. In such cases, the predicted heat transfer coefficient should be compared and calibrated to local experimental values, which might require a different data reduction procedure.

It is therefore important to understand the limits of conventional 1-D data reduction and the significance of differences in the heat transfer coefficient results when a more complex two-dimensional (2-D model) is used. To the authors' knowledge, there are no existing studies in the open literature that have explored the effect of a different data analysis method on experimental heat transfer coefficient values.

In this study, we explored two different data analysis methods for flow boiling experiments done in a tube heated by the Joule effect. The first benchmark data reduction relied on the hypothesis of 1-D heat transfer inside the heated metal tube, whereas the second, new method considered both radial and circumferential heat transfer inside the channel. These two procedures were then applied on a comprehensive database made up of different fluids and operating conditions to provide statistical analysis of the calculated differences and hence define the possible uses of complex 2-D data analysis in some engineering applications.

\section{Method: Data Reduction Procedures}

\subsection{Typical Arrangements for Flow Boiling Experiments}

A typical flow boiling experiment requires that the operating conditions in terms of mass flux $G$, heat flux $q$, saturation temperature $T_{\text {sat }}$, and vapor quality $x$ are fixed and controlled before the measurement section, consisting of a heated single tube or a multiminichannel heat spreader. In the latter case, the investigation mainly concerns the maximum heat load that can be handled before a thermal crisis $[19,20]$. A basic test rig that is able to perform flow boiling experiments on a single tube is shown in Figure 1 [21]. The subcooled refrigerant is driven by means of a pump through a preheating section, in which the heat load is modulated in order to obtain a specific local vapor quality at the inlet of the measurement section. The saturated vapor then enters the test tube, in which heat can be provided either by the Joule effect (with an electric voltage applied to the metal tube itself [22-24] or with a heating device thermally connected to the channel [15]) or by means of hot water flowing 
outside, as experimented by [25-27]. Generally, the test tube is designed to have a slight vapor quality variation along the heated section in order to obtain local heat transfer coefficient values. In some cases, however, the fluid at the tube inlet can still be in subcooled conditions [28], and the entire evaporation takes place in the measurement section by reaching the onset and completion of dryout $[29,30]$.

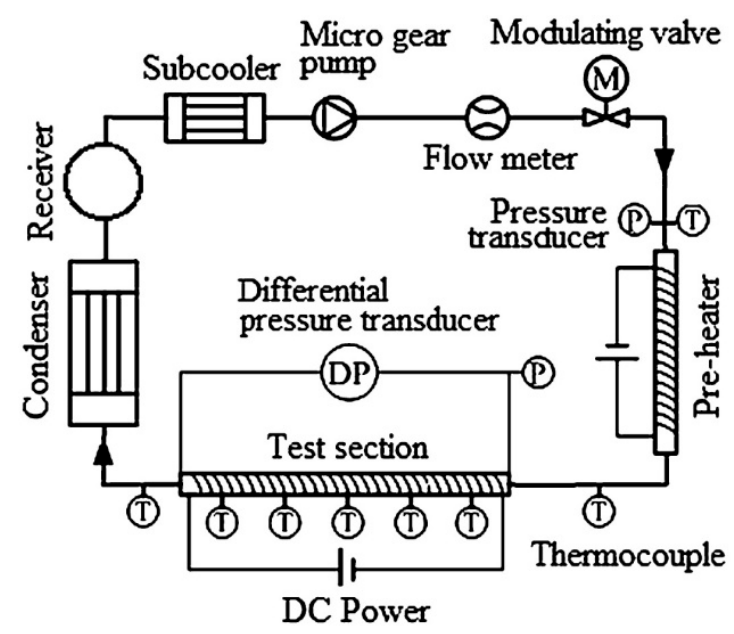

Figure 1. Typical test facility that can be used for flow boiling experiments on a single tube. Sketch taken from [21].

The local heat transfer coefficient, evaluated at a particular position on the tube's surface, as shown in Figure 2, is typically a function of the local operating parameters in terms of vapor quality, imposed heat flux, saturation temperature, mass flux, and, obviously, the working fluid employed.

$$
h=f\left(x, q, T_{\text {sat }}, G, \text { fluid }, \ldots\right),
$$

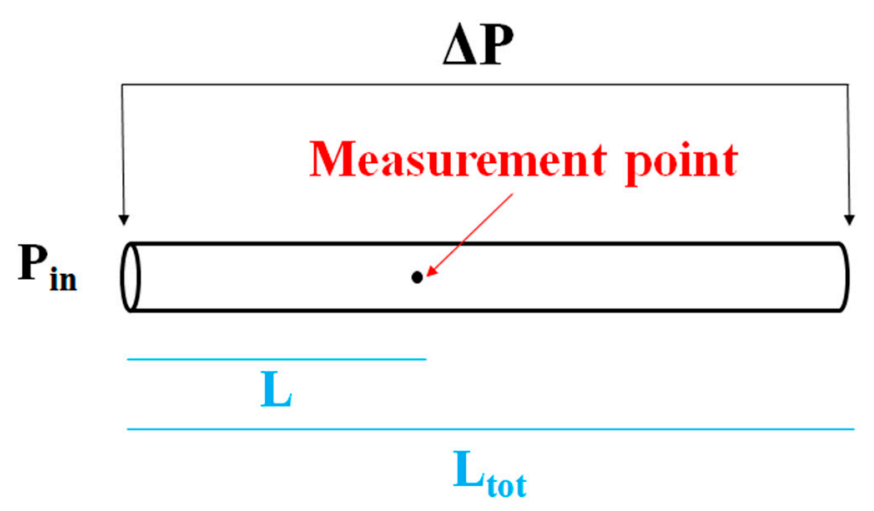

Figure 2. Single-tube heated test section and heat transfer coefficient measurement point.

Among the test conditions, the evaluation of mass flux $G$ for a single tube is performed using the measured mass flow rate $\dot{m}$ and the channel cross section $A$ :

$$
G=\frac{\dot{m}}{A}
$$

The saturation pressure in the test section measurement point (see Figure 2) is generally obtained with measured inlet pressure $P_{\text {in }}$ and total pressure drop $\Delta P$ by considering a constant pressure gradient along the heated section. Although widely used [22,31], this simple approach may actually lose its practicability when the vapor quality in the tube increases significantly, leading to non-negligible pressure gradient variations. The corresponding saturation temperature $T_{s a t}$ in the measurement point 
is a function of the sole local pressure for pure fluids and also of the local enthalpy in the case of mixtures exhibiting a nonazeotropic behavior, for which the temperature glide during evaporation is consistent. The local enthalpy $i$ also allows evaluation of the vapor quality in the measurement point, and it is typically obtained by performing an energy balance on both preheater and measurement sections:

$$
\begin{gathered}
P=P_{\text {in }}-\frac{L}{L_{\text {tot }}} \Delta P, \\
T_{\text {sat }}=f_{2}(P, i), \\
x=f_{3}(P, i), \\
i=i_{\text {in, preh }}+\frac{\dot{Q}_{\text {preh }}+\dot{Q} \cdot \frac{L}{L_{\text {tot }}},}{\dot{m}}
\end{gathered}
$$

The imposed heat flux $q$ is finally calculated according to the heating method using either an energy balance on the secondary fluid [27] or the Ohm law for electrical heating.

The experimental evaluation of the local heat transfer coefficient follows the Newton equation in Equation (7), which uses the inner wall heat flux $q_{i}$ and the inner tube wall superheating $\Delta T_{w}$, defined as the temperature difference between the heated wall and the saturated fluid:

$$
h=\frac{q_{i}}{\Delta T_{\text {wall }}}=\frac{q_{i}}{T_{\text {wall }, i}-T_{\text {sat }}}
$$

In this study, we focused on possible methods to evaluate the local heat transfer coefficient in a single metal tube, in which multiple thermocouples were fixed on the external surface for measurement of the outer wall temperature; the heat flux was imposed by means of electrical current directly applied on the channel itself. Specifically, two different data reductions were examined for a tube in which four thermocouples were glued circumferentially on the external surface in the top $\left(\theta=0^{\circ}\right)$, bottom $\left(\theta=180^{\circ}\right)$, and left and right side $\left(\theta=90^{\circ}\right.$ and $\theta=270^{\circ}$, respectively) positions with even spacing, as shown in Figure 3.

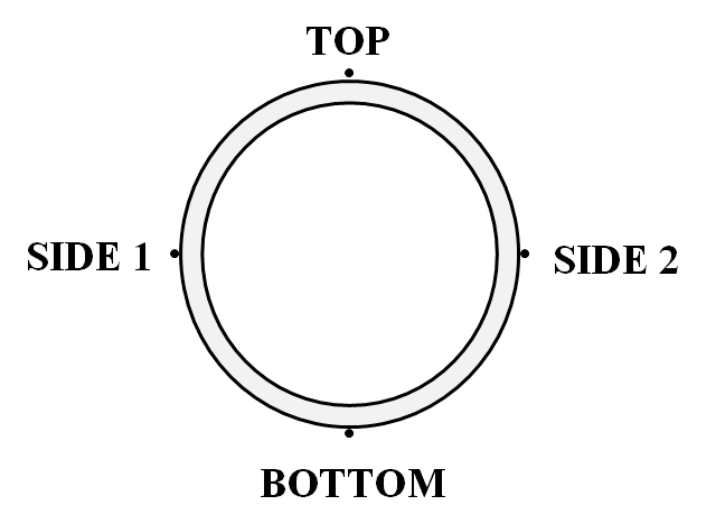

Figure 3. Cross-sectional view of the measurement point considered for the present analysis. Four thermocouples were evenly distributed for evaluation of the outer wall temperature.

\subsection{Conventional 1-D Data Reduction}

According to the conventional 1-D data reduction approach, the temperature field in a metal tube is 1-D in the radial direction. The wall heat flux of Equation (7) is considered uniform when referring 
to the internal heat transfer surface and evaluated as the electrical heat given by the Joule effect minus the possible heat losses occurring due to a nonperfect insulation of the test tube:

$$
q_{i}=\frac{V \cdot I-\dot{Q}_{\text {loss }}}{\pi \cdot d \cdot L_{\text {tot }}}
$$

The inner wall temperature is calculated using the thermocouple measurement at the outer tube surface with the hypothesis of isotropic and homogeneous tube material. Uniform heat flux applied on the external surface is provided by electrical heating and 1-D heat transfer in the radial direction. The boundary conditions can be expressed as Equation (9), in which $\lambda_{t u b e}$ is the metal tube thermal conductivity, and $d$ and $D$ are the inner and outer diameters, respectively:

$$
\left.\lambda_{\text {tube }} \frac{d T}{d r}\right|_{r=\frac{D}{2}}=q_{o}=q_{i} \frac{d}{D} ; \quad T\left(\frac{D}{2}\right)=T_{\text {wall }, o r}
$$

For each thermocouple position, Equation (10) can therefore be applied:

$$
T_{\text {wall }, i}=T_{\text {wall }, o}-\frac{q_{o} D}{2 \lambda_{\text {tube }}} \ln \left(\frac{D}{d}\right),
$$

The local heat transfer coefficient for each measurement point and thermocouple location is thus calculated with Equation (7) by keeping the hypothesis of uniform internal and external imposed heat fluxes.

The cross-sectional average heat transfer coefficient can still be obtained with Equation (7) using the average inner wall temperature:

$$
T_{\text {wall, }, \text { ave }}=\frac{T_{\text {wall, }, \text { top }}+T_{\text {wall }, i, \text { bot }}+2 \cdot T_{\text {wall }, i, \text { side }}}{4},
$$

\subsection{2-D Data Reduction}

According to the 2-D data reduction approach, a two-dimensional temperature field is considered in a metal tube. This method provides a circumferential local heat transfer coefficient profile and may be particularly useful in cases of significant asymmetry of heat transfer. The 2-D temperature field in the channel is evaluated by means of the finite volume method, which involves dividing the tube cross section in several elements with $(\theta, r)$ coordinates by applying the general heat transfer equation:

$$
\frac{1}{r} \frac{\partial}{\partial r}\left(r \frac{\partial T}{\partial r}\right)+\frac{1}{r^{2}} \frac{\partial^{2} T}{\partial \theta^{2}}=0
$$

As for the boundary conditions, the outer heat flux is considered uniform, representing the external boundary condition:

$$
q_{o}=\frac{V \cdot I-\dot{Q}_{\text {loss }}}{\pi \cdot D \cdot L_{\text {tot }}}
$$

On the internal surface, the heat transfer coefficient at the top $\left(\theta=0^{\circ}\right)$, bottom $\left(\theta=180^{\circ}\right)$, and side $\left(\theta=90^{\circ}\right.$ and $\left.\theta=270^{\circ}\right)$ locations are presumed. As a first attempt, the values in the singular points can be chosen from the conventional 1-D data reduction (using Equations (7), (8) and (10)). The heat transfer coefficient profile in the azimuthal direction $h=f(\theta)$ may be constructed by imposing its passage through the three singular points and, for symmetry reasons, the minimum or maximum heat transfer coefficient values at the top and the bottom points, as shown in Equations (14) and (15):

$$
h(\theta=0)=h_{\text {top }} ; h\left(\theta=90^{\circ}\right)=h_{\text {side }} ; h\left(\theta=180^{\circ}\right)=h_{\text {bottom }},
$$




$$
\left.\frac{\partial h}{\partial \theta}\right|_{\theta=0}=0 \text { and }\left.\frac{\partial h}{\partial \theta}\right|_{\theta=180^{\circ}}=0,
$$

Different functions can then be considered with equivalent results owing to the weak heat transfer coefficient variation along the tube profile. For simplicity reasons, a fourth-order polynomial equation was considered in this study as it requires an easier calculation and a faster computational procedure:

$$
h(\theta)=a \cdot \theta^{4}+b \cdot \theta^{3}+c \cdot \theta^{2}+d \cdot \theta+e,
$$

with the heat transfer coefficient profile, the second boundary condition at the inner wall is given as shown in Equation (17), and the heat transfer problem can be solved:

$$
q_{i}(\theta)=h(\theta) \cdot\left(T_{\text {wall }, i}(\theta)-T_{\text {sat }}\right),
$$

The final step is the comparison between the measured outer wall temperatures and the values obtained by the model by gradually adjusting the presumed heat transfer coefficient at the singular points up to the final convergence, which is reached when the errors in the outer wall temperatures are all below a chosen threshold. The complete algorithm displaying the iterative procedure is shown in Figure 4.

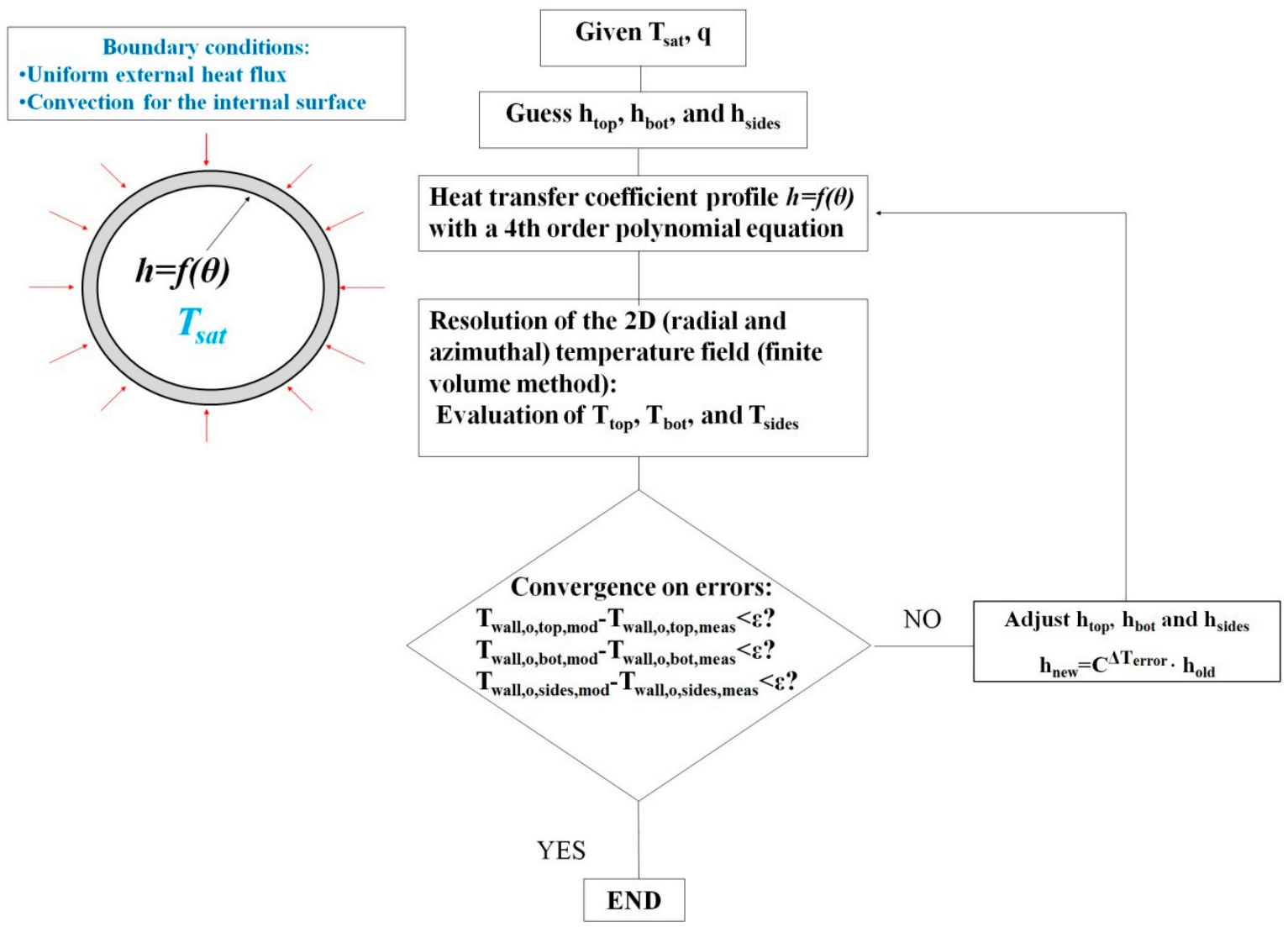

Figure 4. Algorithm for the two-dimensional (2-D) data reduction.

The cross-sectional average heat transfer coefficient can be obtained with Equation (7) using the mean inner wall temperature and the mean heat flux value on the whole circumferential profile.

The adjusting constant $C$ and the error threshold $\varepsilon$ should be accurately calibrated to avoid long computational times and unstable solutions. For the present analysis, the values of $C=1.15$ and $\varepsilon=0.003{ }^{\circ} \mathrm{C}$ were chosen. With regard to the meshing process, the number of elements in the radial 
direction was chosen after a careful sensitivity analysis carried out using the 2-D model as a numeric 1-D solution (deactivating the conduction term in the circumferential direction) with several values of $d r$ and comparison of the inner tube wall temperature to the analytical solution of Equation (10). The analysis was performed by considering an imposed external heat flux $q_{0}$ equal to $7500 \mathrm{~W} / \mathrm{m}^{2}$, a measured outer wall temperature of $38.8^{\circ} \mathrm{C}$, and internal and external diameters of 6 and $8 \mathrm{~mm}$, respectively, with a thermal conductivity of $16.26 \mathrm{~W} / \mathrm{mK}$ (AISI 304 stainless steel tube). The sensitivity analysis results are shown in Figure 5 With radial elements smaller than $0.025 \mathrm{~mm}$, the accuracy gain was negligible with temperature differences close to the residual error $\varepsilon$ allowed in the 2-D model, whereas the computation time rose dramatically. In the present study, the radial elementary unit was chosen as $d r=0.025 \mathrm{~mm}$, whereas the metal tube was further divided into 240 items in the circumferential direction $(d \theta=0.026 \mathrm{rad})$.

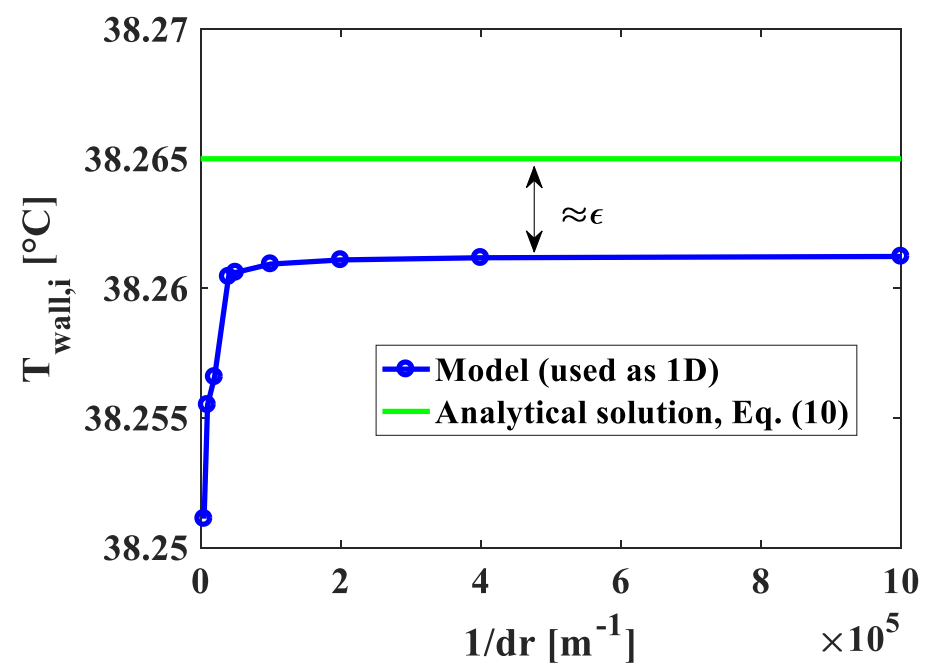

Figure 5. Sensitivity analysis of the mesh in the radial direction. Conditions: imposed external heat flux $q_{o}=7500 \mathrm{~W} / \mathrm{m}^{2}$, measured outer wall temperature $=38.8^{\circ} \mathrm{C}$, internal diameter $d=6 \mathrm{~mm}$, external diameter $D=8 \mathrm{~mm}$, thermal conductivity $\lambda_{\text {tube }}=16.26 \mathrm{~W} / \mathrm{mK}$.

\section{Result Comparison and Statistical Analysis}

\subsection{Result Comparison}

The two different procedures were compared and examined using flow boiling data available in open literature. Although numerous studies have been carried out on single tubes with electrical heating, most of them do not provide the local heat transfer coefficient values in the circumferential direction, preventing any 2-D data reduction analysis. In this study, flow boiling data of refrigerants R1233zd and ethanol were selected from some of our previous publications [32,33]. All the experiments were carried out in a horizontal stainless steel channel (AISI 304) with an internal diameter of $6 \mathrm{~mm}$ and a wall thickness of $1.0 \mathrm{~mm}$. The electrical heating was provided, and four thermocouples were used (at the top, bottom, and left and right sides of the tube, as shown in Figure 3) for the measurement of the outer wall temperature. More details on the test facility, measurement section, uncertainty analysis calculation, and evaluation of the heat losses can be found in the original references $[32,33]$. The chosen working fluids have a very low, reduced pressure (i.e., the ratio of the saturation pressure to the critical pressure) compared to other conventional refrigerants. In these conditions, the convective heat transfer contribution should be significant with respect to the nucleation phenomena, leading to inertia-driven heat transfer [34] with possible asymmetry and peculiar heat transfer coefficient trends with vapor quality and mass flux.

Figure 6 shows the local heat transfer coefficients as a function of the vapor quality for refrigerant R1233zd(E) using conventional 1-D data reduction. The following average operating conditions were 
applied: mass flux $G$ of $219 \mathrm{~kg} / \mathrm{m}^{2} \mathrm{~s}$, inner wall heat flux $q_{i}$ of $2.47 \mathrm{~kW} / \mathrm{m}^{2}$, and saturation temperature $T_{\text {sat }}$ of $34.8^{\circ} \mathrm{C}$. The local heat transfer coefficient showed a typical convective behavior, supported also by a very low imposed heat flux that further restrained the nucleative contribution to the heat transfer. The whole evolution of the heat transfer coefficient versus the vapor quality was divided in three different zones, as highlighted in Figure 6. For low vapor qualities (zone 1), a slug flow likely occurred, with intermittent passages of vapor in the channel and a different liquid film thickness at the top and bottom walls due to the gravity force. A higher liquid film thickness at the bottom side of the tube involved a higher thermal resistance and therefore a lower heat transfer coefficient, as also shown in the experiments of Grauso et al. [35]. For intermediate vapor qualities (zone 2), there were no significant differences in the local heat transfer coefficients, meaning that the flow pattern occurring was likely an annular flow, with the heated wall surrounded by an almost uniform liquid film thickness that eventually became thinner at the top side, leading to slight asymmetries in the heat transfer coefficient at vapor qualities around 0.8. The last zone, i.e., zone 3, is shown in Figure 6 for vapor qualities higher than 0.85 . In these conditions, the liquid film thickness gradually dried out, starting from the top side of the tube due to the gravity force and penalizing the corresponding heat transfer coefficient. The dryout phenomenon was completed for the last point of the trend in Figure 6, in which all local heat transfer coefficients assumed the same value, meaning that the heated tube was completely surrounded by the vapor phase, and the remaining liquid fraction was likely to be dispersed and dragged by the vapor core.

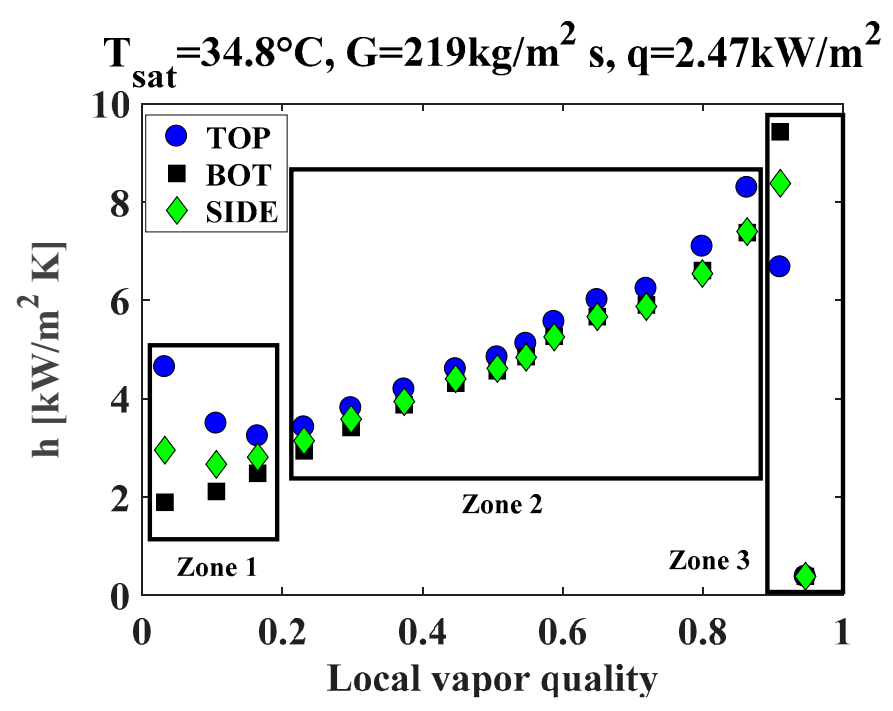

Figure 6. Local heat transfer coefficients as a function of the vapor quality for refrigerant $\mathrm{R} 1233 \mathrm{zd}(\mathrm{E})$ at saturation temperature $T_{\text {sat }}=34.8^{\circ} \mathrm{C}$, mass flux $G=219 \mathrm{~kg} / \mathrm{m}^{2} \mathrm{~s}$, and inner wall heat flux $q_{i}=2.47 \mathrm{~kW} / \mathrm{m}^{2}$. The local values were obtained using the one-dimensional (1-D) solution.

Three experimental points from Figure 6 were isolated from the corresponding three zones, and the temperature fields in the heated metal tube are shown in Figure 7. Figure 7a,c,e refers to the solution of the 2-D model for vapor qualities of $0.03,0.51$ and 0.91 , respectively, whereas the conventional 1-D solution of Equation (10) for the same experimental points is given in Figure $7 b, d, f$. The diagrams of the 1-D data reduction provide a uniform external and internal wall temperature for each thermocouple area of influence and were obtained with the 2-D model by setting the circumferential heat transfer conductive term as zero. With a vapor quality of 0.03 , corresponding to a possible slug or intermittent flow (zone 1 in Figure 6), the temperature field of the 2-D model (Figure 7a) was significantly different than that obtained with the conventional data reduction (Figure $7 \mathrm{~b}$ ), in which the four independent measurement areas were clearly distinguishable. It was the same case in the dryout zone at a vapor quality of 0.91 (see Figure 7e,f). With an intermediate vapor quality of 0.51 corresponding to a symmetric annular flow, there were no clear differences in the temperature solutions of the two different data 
reductions (Figure $7 \mathrm{c}, \mathrm{d}$ ), with a weak temperature gradient passing from $35.43^{\circ} \mathrm{C}$ at the top inner wall temperature to $35.59^{\circ} \mathrm{C}$ at the bottom outer wall temperature.

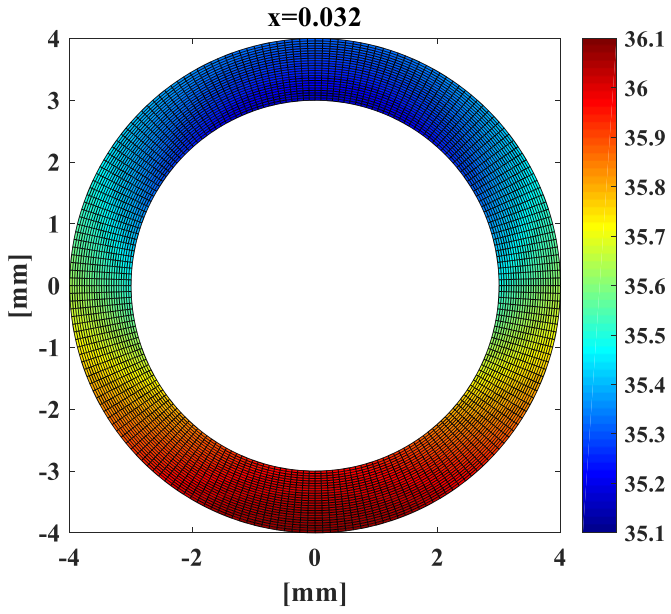

(a)

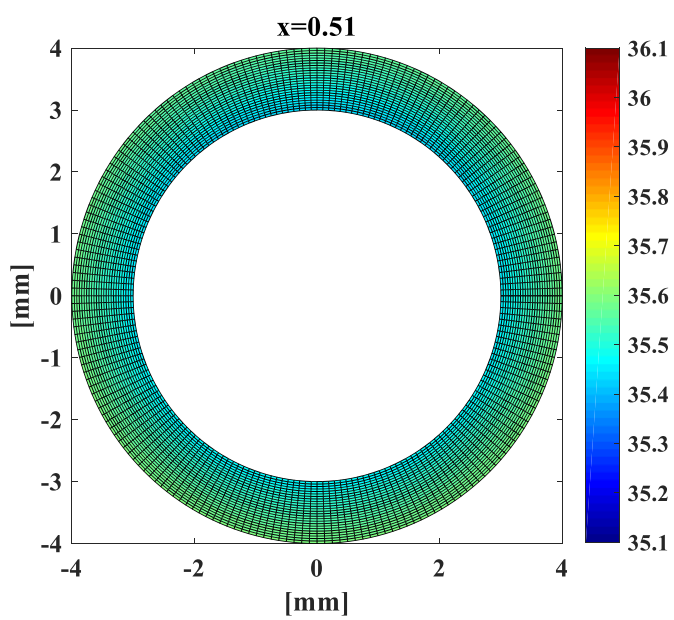

(c)

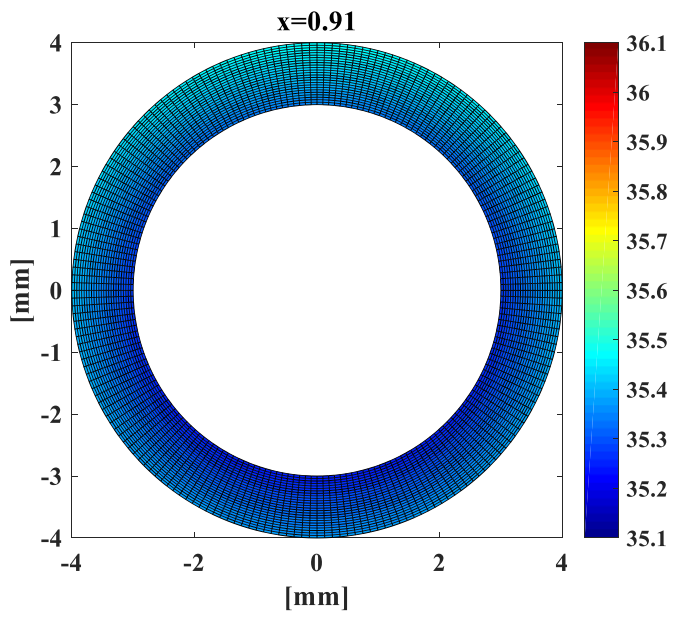

(e)

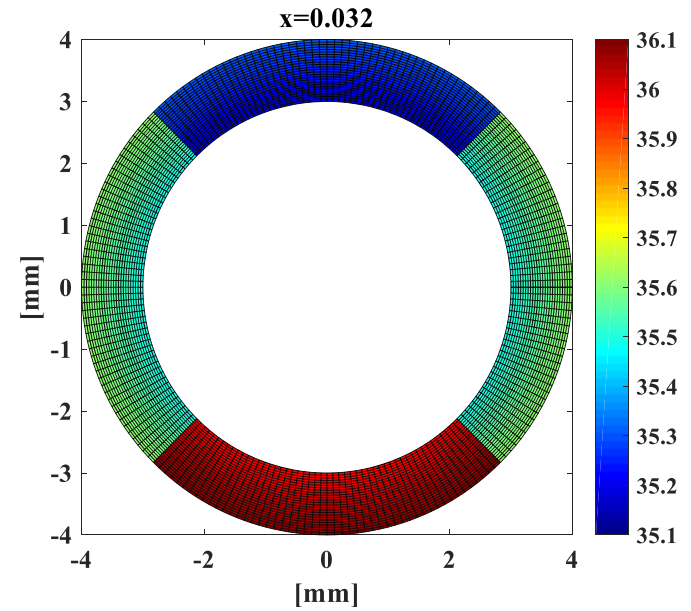

(b)

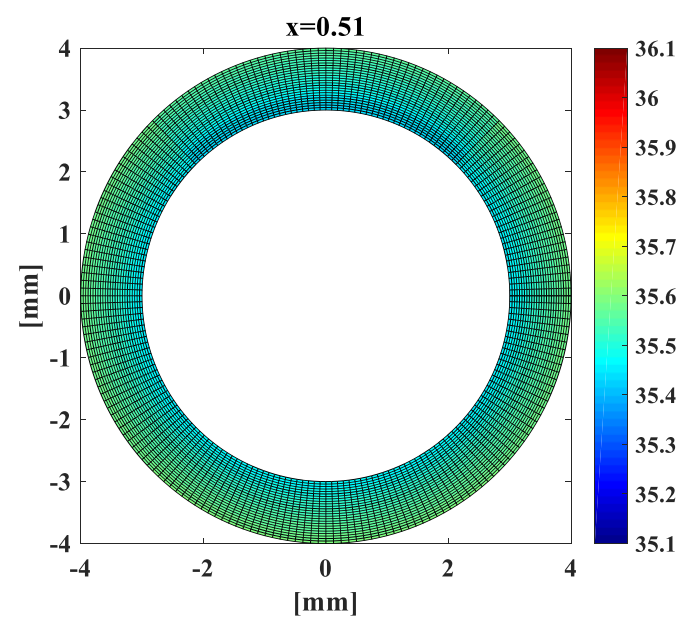

(d)

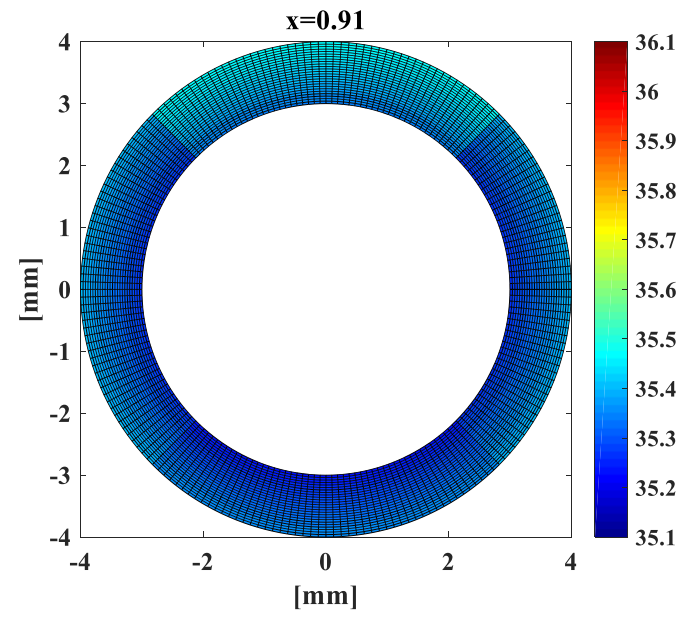

(f)

Figure 7. Temperature field in the metal tube for three experimental points taken from Figure 6. (a,c,e) solutions of the 2-D model. $(\mathbf{b}, \mathbf{d}, \mathbf{f})$ analytical solutions of the conventional 1-D method. 
The wall superheat (i.e., the difference between the inner wall temperature and the saturation temperature) profiles around the tube's inner surface for the three different investigated vapor qualities is summarized in Figure 8 for both the 2-D model and the conventional 1-D data reduction method. For symmetry reasons, the circumferential angle $\theta$ in the diagrams is confined between the top and bottom positions $\left(0^{\circ}\right.$ and $180^{\circ}$, respectively). The wall superheat increased from top to bottom at low vapor qualities, whereas it remained substantially uniform in the case of symmetric annular flow before finally showing a decreasing trend in the dryout region. For the conventional 1-D solution (Figure $8 b$ ), although preserving the mean value in the whole profile, the stepwise trends caused a local accuracy loss, especially for the most asymmetric experimental point at $x=0.03$.

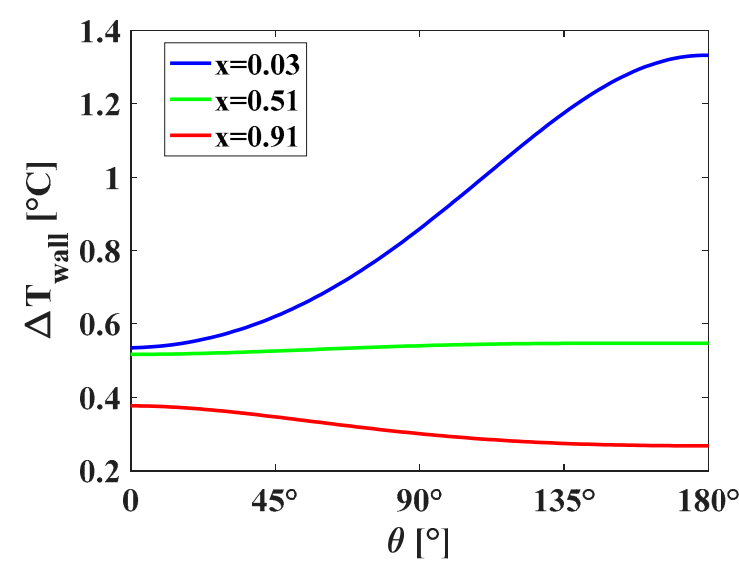

(a)

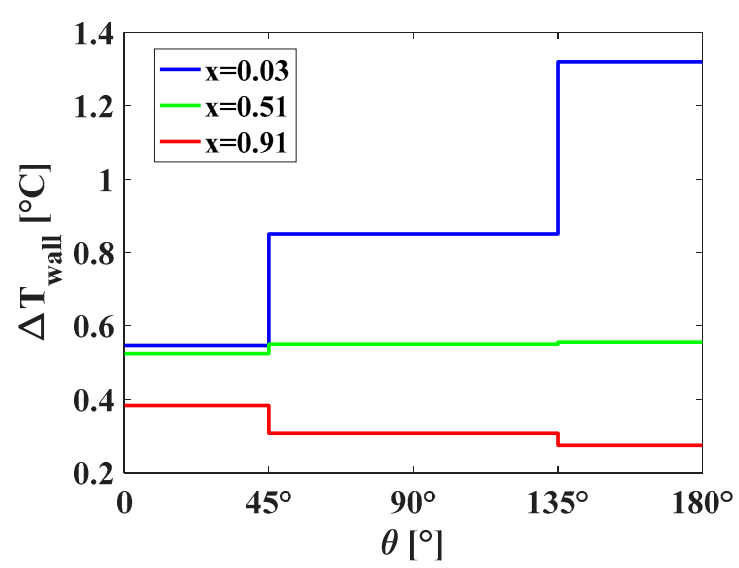

(b)

Figure 8. Wall superheat profiles for the three vapor qualities corresponding to the three different heat transfer coefficient zones in Figure 6. (a) 2-D data reduction; (b) conventional 1-D data reduction.

The inner wall heat flux profiles in the metal tube for the three considered zones and the two models are shown in Figure 9a,b, respectively. It is worth noting that the 1-D solution provided a uniform heat flux at both the outer and inner surfaces of the heated tube, as specified by Equations (8) and (13). The 2-D model, however, used a more realistic hypothesis of only external heat flux uniformity due to the imposed electrical heating, and the inner value changed continuously (see Figure 9a) according to the temperature field, as in Equation (17).

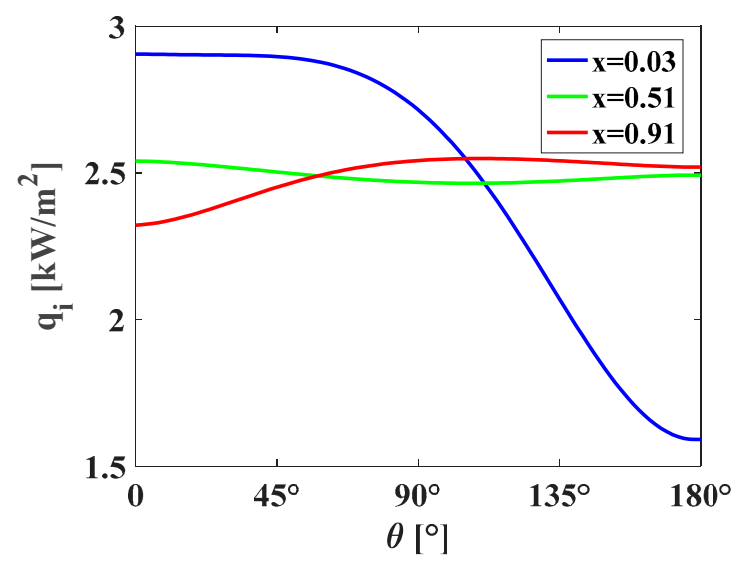

(a)

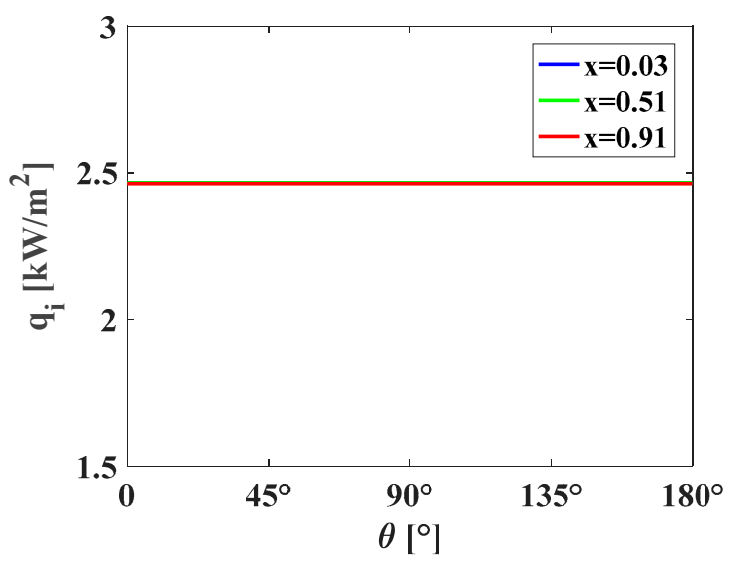

(b)

Figure 9. Wall heat flux profiles for the three vapor qualities corresponding to the three different heat transfer coefficient zones in Figure 6. (a) 2-D data reduction; (b) conventional 1-D data reduction. 
Finally, the local heat transfer coefficient profiles for the three zones are shown in Figure 10a,b for the two data reductions, respectively. Consistent with the previous diagrams, although preserving the same mean values, the trends obtained with the analytical 1-D solution could lead to significant local heat transfer coefficient discrepancies. For a vapor quality of $x=0.03$, between $\theta=0^{\circ}$ and $\theta=45^{\circ}$ (corresponding to the "top" thermocouple measurement area), the 2-D heat transfer coefficient varied from approximately 5500 to $4900 \mathrm{~W} / \mathrm{m}^{2} \mathrm{~K}$, whereas the 1-D model provided a uniform value of $4511 \mathrm{~W} / \mathrm{m}^{2} \mathrm{~K}$. For the same vapor quality, the heat transfer coefficient at the bottom area (between $135^{\circ}$ and $180^{\circ}$ ) passed from around 1700 to $1200 \mathrm{~W} / \mathrm{m}^{2} \mathrm{~K}$ compared to the constant value of $1878 \mathrm{~W} / \mathrm{m}^{2} \mathrm{~K}$ obtained with the analytical solution. Similar findings were made for the dryout zone (at a vapor quality of $x=0.91$ ), whereas the differences between the two data reductions were almost negligible for the symmetric experimental condition of $x=0.51$.

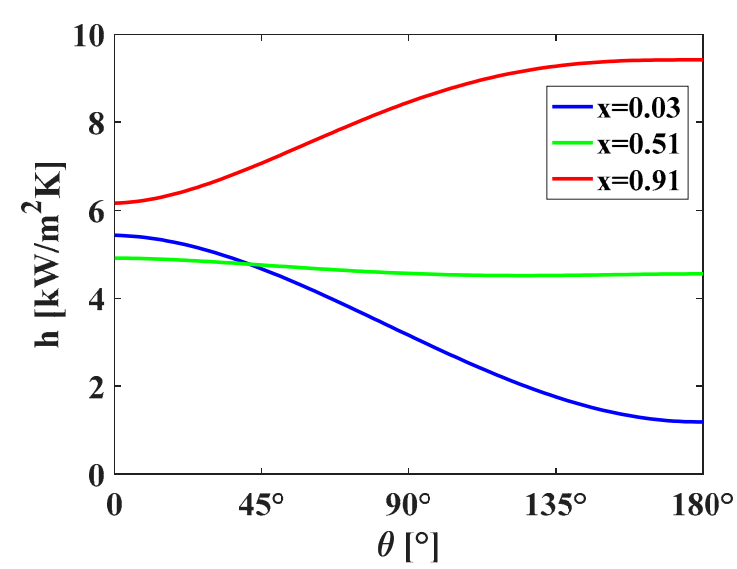

(a)

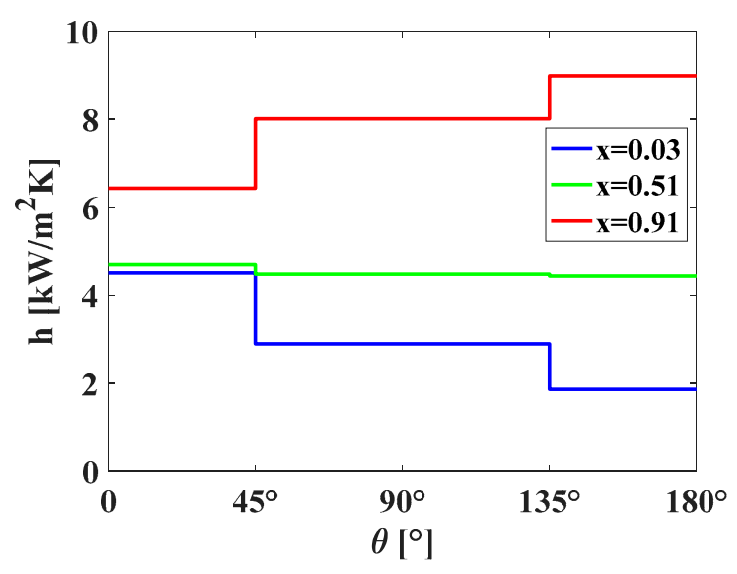

(b)

Figure 10. Heat transfer coefficient profiles for the three vapor qualities corresponding to the three different heat transfer coefficient zones in Figure 6. (a) 2-D data reduction; (b) conventional 1-D data reduction.

For the three experimental points examined, the relative deviations of the local heat transfer coefficient profile using the two different data reduction procedures is shown in Figure 11. In the case of symmetric behavior $(x=0.51)$, the discrepancies were almost negligible as they never exceeded $5 \%$. For asymmetric trends, the relative deviations reached $15 \%$ in the dryout region $(x=0.91)$ and around $60 \%$ in the intermittent zone $1(x=0.03)$. Higher local deviations (up to $84 \%$ ) in the dryout zone were observed in tests taken at different operating conditions. The overall mean absolute percentage error (MAPE) on the profile was calculated according to the following expression:

$$
M A P E=\frac{1}{N} \sum_{i=1}^{N} \frac{\left|h_{2 D}-h_{1 D}\right|}{h_{1 D}} \cdot 100 ; \quad N=\frac{2 \pi}{d \theta} .
$$

The MAPE values passed from $2.9 \%$ in the annular flow region up to $6.9 \%$ and $24.1 \%$ in the dryout and intermittent zones, respectively. 


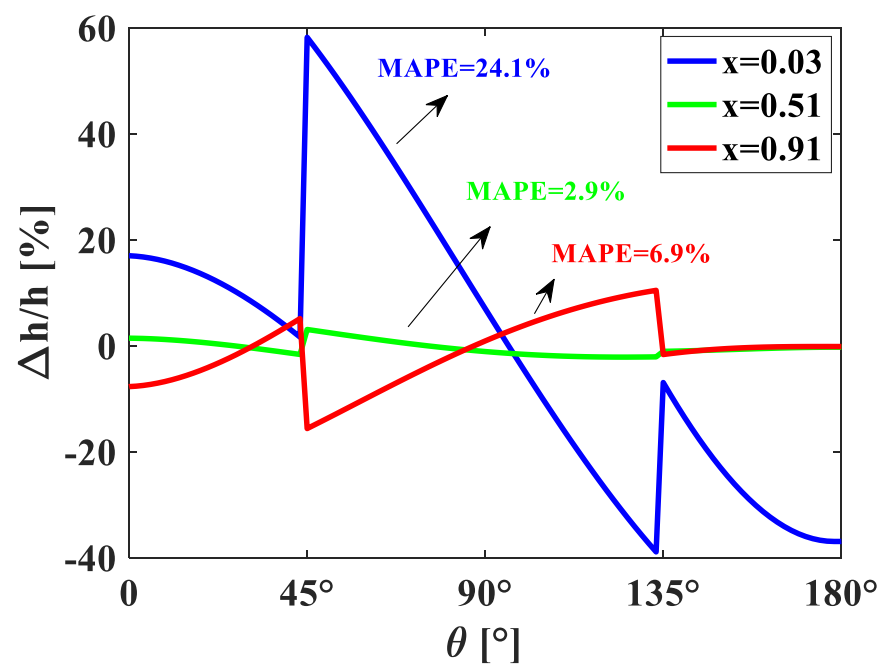

Figure 11. Relative deviation of the local heat transfer coefficients along the tube using the 2-D model and the 1-D analytical solution.

\subsection{Statistical Analysis}

A statistical analysis was finally carried out on the whole experimental database taken from Mastrullo et al. [32,33]. The operating conditions are summarized in Table 1 for the two working fluids, with a total of 417 tests. The experimental uncertainties of the heat transfer coefficient and wall heat flux obtained by the authors according to the conventional 1-D data reduction are shown in Table 2. For each experimental point, the maximum deviation and the MAPE, defined in Equation (18), between the two data reduction procedures on the heat transfer coefficient profile were calculated and examined.

Table 1. Experimental conditions and number of tests considered for the statistical analysis.

\begin{tabular}{cccccc}
\hline Fluid & $\mathbf{G}\left(\mathbf{k g} / \mathbf{m}^{\mathbf{2}} \mathbf{s}\right)$ & $\mathbf{T}_{\text {sat }}\left({ }^{\circ} \mathbf{C}\right)$ & $\mathbf{q} \mathbf{( k W / \mathbf { m } ^ { 2 } )}$ & $\mathbf{x}$ & $\mathbf{N}_{\text {test }}$ \\
\hline Ethanol & $60-120$ & $25-85$ & $2.5-20$ & $0.01-0.99$ & 82 \\
R1233zd & $150-500$ & $25-65$ & $2.5-40$ & $0.01-0.99$ & 335 \\
\hline
\end{tabular}

Table 2. Provided experimental uncertainties of the heat transfer coefficient and heat flux $[32,33]$.

\begin{tabular}{ccc}
\hline Parameter & $\begin{array}{c}\text { Max Uncertainty for } \\
\text { R1233zd(E) Data }\end{array}$ & $\begin{array}{c}\text { Max Uncertainty for } \\
\text { Ethanol Data }\end{array}$ \\
\hline Heat flux $q$ & $\pm 0.74 \%$ & $\pm 0.7 \%$ \\
Mean heat transfer coefficient $h_{\text {mean }}$ & $\pm 13 \%$ & $\pm 12 \%$ \\
\hline
\end{tabular}

The MAPE values for the whole profile and those related only to the top, bottom, and side regions of the tube as a function of the vapor quality for the entire database are shown in Figures 12 and 13. The MAPE values in Figure 12 are separated according to the working fluid and the heat transfer coefficient regions, as already presented in Figure 6. The U-shaped trend shows that the greater differences between the two methods were confined at low (below 0.20) and high (above 0.80) vapor qualities. Specifically, the higher MAPE values were restricted to the most asymmetric heat transfer regions (zones 1 and 3), whereas the calculated mean errors were all below $5 \%$ in the case of symmetric annular flow. No significant differences were observed for the two fluids. The lower overall MAPE for the ethanol was due to the lack of experimental data on high vapor quality, thus avoiding the dryout condition. It is worth noting that higher errors were also related to low imposed electrical heat fluxes, as shown in Figure 12b. In fact, with an increasing heat flux, the nucleate boiling contribution became significant, with lower chances of asymmetric heat transfer behavior. 


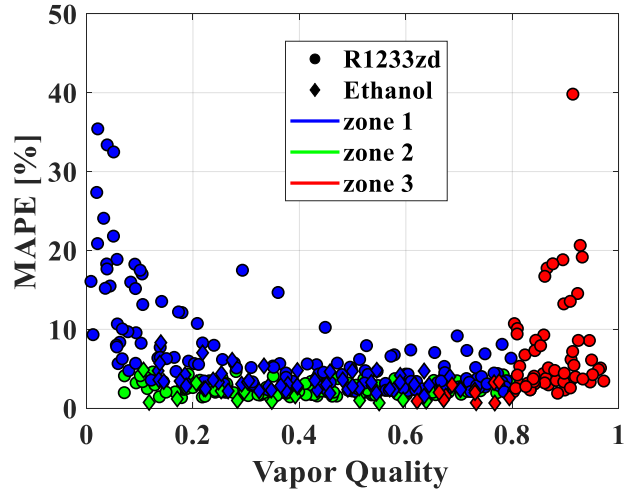

(a)

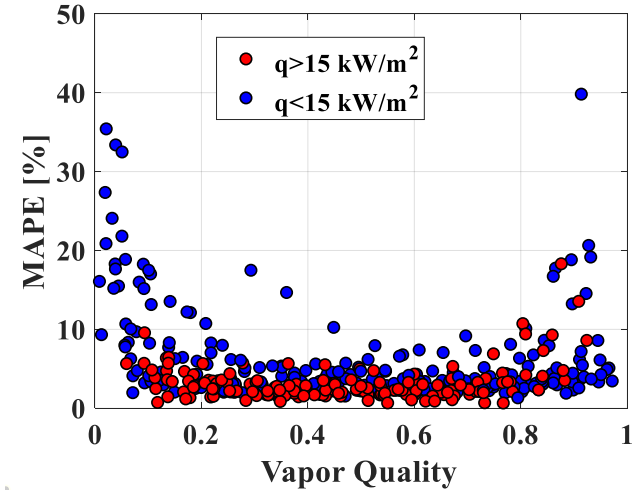

(b)

Figure 12. Mean absolute percentage error (MAPE) values as a function of the local vapor quality for the collected database. Different markers and colors refer to (a) working fluid and heat transfer behavior zones and (b) average internal heat flux.

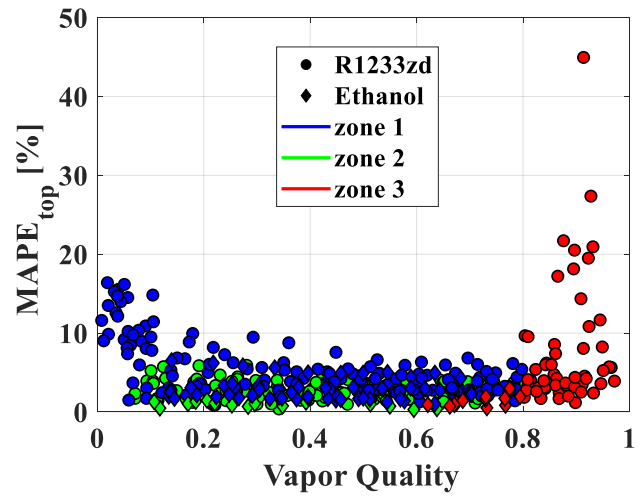

(a)

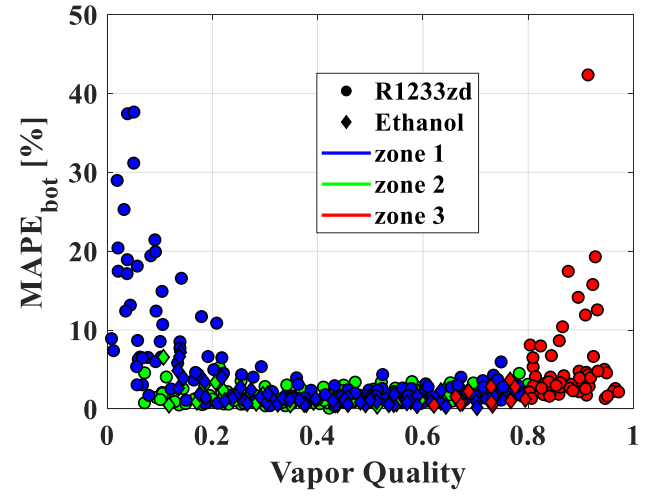

(b)

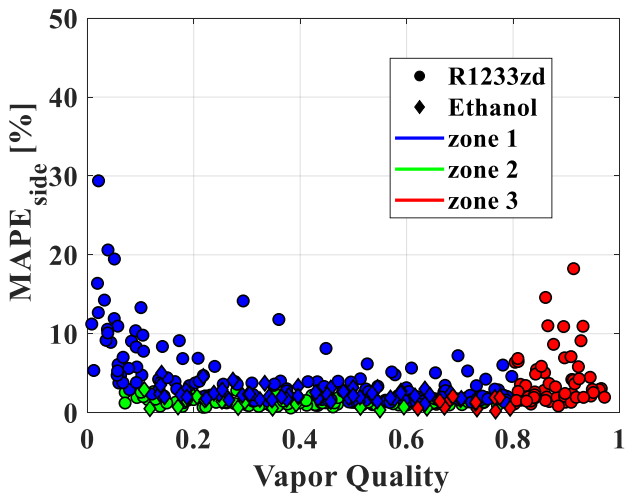

(c)

Figure 13. MAPE values calculated only for the (a) top, (b) bottom and (c) side regions of the tube as a function of the vapor quality for the collected database. Different markers and colors refer to the working fluid and the heat transfer behavior zones.

Figure 13 shows the MAPE values related only to the top (from $0^{\circ}$ to $45^{\circ}$ ), bottom (from $135^{\circ}$ to $180^{\circ}$ ), and side (from $45^{\circ}$ to $135^{\circ}$ ) regions of the tube for the entire database, separated by working fluid and heat transfer zones. With respect to the top and bottom local MAPE values, which reached up to $45 \%$ in dryout conditions, lower mean percentage errors were instead observed for the side region of the tube, with a maximum value of around $30 \%$ in the intermittent flow asymmetric zone. A summary 
of all the statistical analyses for several subsets of data is provided in Table 3, including the mean values of the MAPE index as well as the maximum relative deviation between the two models. Besides relatively low mean MAPE values, equal to a maximum of around $6 \%$ in the asymmetric zone, it is important to remark that the local discrepancies between the two analyzed data reductions could be consistent, reaching up to $130 \%$ in the most asymmetric regions for the present database.

Table 3. Mean MAPE values calculated on the whole profile and on specific sectors for several subsets of data.

\begin{tabular}{cccccc}
\hline & Max $\mathbf{\Delta h} / \mathbf{h} \mathbf{( \% )}$ & MAPE (\%) & MAPE $_{\text {top }}(\mathbf{\% )}$ & MAPE $_{\text {bot }}(\mathbf{\%})$ & MAPE $_{\text {side }}(\mathbf{\% )}$ \\
\hline Zone 1 (intermittent) & 130 & 6.2 & 4.7 & 4.3 & 3.9 \\
\hline Zone 2 (symmetric annular) & 13 & 2.3 & 2.5 & 1.5 & 1.3 \\
\hline Zone 3 (dryout) & 84 & 6.4 & 6.5 & 4.9 & 3.6 \\
\hline $\mathrm{q}<15 \mathrm{~kW} / \mathrm{m}^{2}$ & 130 & 5.6 & 5.2 & 4.0 & 3.4 \\
\hline $\mathrm{q}>15 \mathrm{~kW} / \mathrm{m}^{2}$ & 36 & 3.2 & 2.4 & 2.3 & 2.1 \\
\hline Ethanol & 20 & 2.9 & 2.3 & 1.6 & 1.9 \\
\hline R1233zd(E) & 130 & 5.3 & 4.7 & 3.9 & 3.2 \\
\hline Overall & 130 & 4.8 & 4.2 & 3.4 & 2.9 \\
\hline
\end{tabular}

\section{Conclusions and Perspective on Applicability of 1-D and 2-D Models}

In the present study, the benchmark 1-D data reduction method for evaluation of local heat transfer coefficient inside a single metal tube electrically heated by the Joule effect was compared with a new method that considers both radial and circumferential heat transfer inside the channel to obtain the 2-D temperature field in the tube and a continuous heat transfer coefficient profile.

By means of experimental flow boiling data taken from published research with ethanol and R1233zd as working fluids, the wall temperature, heat flux, and heat transfer coefficient values were calculated with the two methods for different (symmetric and asymmetric) heat transfer behaviors. A statistical analysis with MAPE evaluation was also performed. The main findings can be summarized as follows:

- For symmetric heat transfer behavior (pure annular flow regime), obtained in the case of average vapor qualities and helped by nucleation for high imposed heat fluxes, the two data reductions were almost equivalent, with maximum heat transfer coefficient deviations in the tube circumferential profile of $13 \%$ and a calculated MAPE equal to $2 \%$.

- The differences became significant in the case of intermittent/slug flow regimes, in which the heat transfer was asymmetric. The mean percentage errors in this case were around $6 \%$, and the maximum deviations between the two methods reached up to $130 \%$.

From an engineering point of view, the following perspectives can be considered:

- The typical 1-D data reduction remains a solid and reliable method for the correct design of evaporators. The average cross-sectional values of heat transfer coefficient do not present substantial differences between 1-D and 2-D data reduction procedures, and there is therefore no point in using the more complex and computationally demanding 2-D model.

- For the advanced design of heat exchangers and heat spreader systems, in which reliable heat transfer coefficient mean values on different sections of the heated tube are required, a 2-D data reduction may be taken into consideration.

- For other purposes, such as high-level modeling of the two-phase flow, a 2-D data reduction is the most reliable method to be employed during experiments performed and used to validate prediction methods that try to correlate the local film thickness to the local heat transfer performance. 
Author Contributions: Data curation, R.M. and A.W.M.; Funding acquisition, R.M., Investigation, R.M. and A.W.M.; Methodology, R.M. and A.W.M.; Writing—original draft, A.W.M.; Writing—review \& editing, R.M.

Funding: This research was funded by "Ministero dell'Istruzione dell'Università e della Ricerca" via the project PRIN2015 "Clean Heating and Cooling Technologies for an Energy Efficient Smart Grid", which is gratefully acknowledged.

Conflicts of Interest: The authors declare no conflict of interest.

\section{Nomenclature}

\begin{tabular}{|c|c|c|}
\hline \multicolumn{3}{|l|}{ Roman } \\
\hline$A$ & channel cross section & $\left(\mathrm{m}^{2}\right)$ \\
\hline$a, b, c, d, e$ & constants of a fourth-order polynomial equation & $(-)$ \\
\hline C & calibrated adjusting constant & $(-)$ \\
\hline$d$ & tube internal diameter & $(\mathrm{m})$ \\
\hline$D$ & tube external diameter & $(\mathrm{m})$ \\
\hline$d r$ & radial step & $(\mathrm{m})$ \\
\hline$d \theta$ & circumferential step & $(\mathrm{m})$ \\
\hline G & mass flux & $\left(\mathrm{kg} / \mathrm{m}^{2} \mathrm{~s}\right)$ \\
\hline$h$ & heat transfer coefficient & $\left(\mathrm{W} / \mathrm{m}^{2} \mathrm{~K}\right)$ \\
\hline$I$ & current & (A) \\
\hline$i$ & enthalpy & $(\mathrm{J} / \mathrm{kg})$ \\
\hline$L$ & length & $(\mathrm{m})$ \\
\hline MAPE & mean absolute percentage error & $(\%)$ \\
\hline$\dot{m}$ & mass flow rate & $(\mathrm{kg} / \mathrm{s})$ \\
\hline$P$ & pressure & $(\mathrm{Pa})$ \\
\hline$q$ & heat flux & $\left(\mathrm{W} / \mathrm{m}^{2}\right)$ \\
\hline RMSE & root mean square error & $\left(\mathrm{W} / \mathrm{m}^{2} \mathrm{~K}\right)$ \\
\hline$\dot{Q}$ & heat load & $(\mathrm{W})$ \\
\hline$T$ & temperature & $\left({ }^{\circ} \mathrm{C}\right)$ \\
\hline$V$ & voltage & $(\mathrm{V})$ \\
\hline$x$ & vapor quality & $(-)$ \\
\hline \multicolumn{3}{|l|}{ Greek } \\
\hline$\Delta$ & difference & $(-)$ \\
\hline$\varepsilon$ & temperature residual threshold & $\left({ }^{\circ} \mathrm{C}\right)$ \\
\hline$\theta$ & angle, circumferential direction & (rad) \\
\hline$\lambda$ & thermal conductivity & $(\mathrm{W} / \mathrm{mK})$ \\
\hline \multicolumn{3}{|c|}{ Subscripts } \\
\hline 1D & related to the 1-D data reduction & \\
\hline $2 \mathrm{D}$ & related to the 2-D data reduction & \\
\hline ave & average & \\
\hline bot & related to the bottom region of the tube & \\
\hline $\mathrm{i}$ & inner wall & \\
\hline in & inlet & \\
\hline meas & measured & \\
\hline $\bmod$ & model & \\
\hline $\mathrm{o}$ & outer wall & \\
\hline preh & preheater & \\
\hline sat & saturation & \\
\hline side & related to the side regions of the tube & \\
\hline top & related to the top region of the tube & \\
\hline tot & total & \\
\hline tube & related to the tube & \\
\hline wall & related to the wall & \\
\hline
\end{tabular}




\section{References}

1. Grinden, B.; Feilberg, N. Analysis of Monitoring Campaign in Europe (REMODECE D10). Available online: https://remodece.isr.uc.pt/ (accessed on 4 October 2019).

2. Kolokotroni, M.; Mylona, Z.; Evans, J.; Foster, A.R. Liddiard, Supermarket energy use in the UK. Energy Procedia 2019, 161, 325-332. [CrossRef]

3. Maratou, A. EU policy update-F-Gas Regulation, HFC taxes \& fiscal incentives for natural refrigerants. In Proceedings of the ATMOshpere Asia 2014-Technology and Innovation, Tokyo, Japan, 3-5 February 2015.

4. Botticella, F.; de Rossi, F.; Mauro, A.W.; Vanoli, G.P.; Viscito, L. Multi-criteria (thermodynamic, economic and environmental) analysis of possible design options for residential heating split systems working with low GWP refrigerants. Int. J. Refr. 2018, 87, 131-153. [CrossRef]

5. Mastrullo, R.; Mauro, A.W.; Viscito, L. Flow boiling of R452A: Heat transfer data, dry-out characteristics and a correlation. Exp. Therm. Fluid Sci. 2019, 105, 247-260. [CrossRef]

6. Lillo, G.; Mastrullo, R.; Mauro, A.W.; Viscito, L. Flow boiling heat transfer, dry-out vapor quality and pressure drop of propane (R290): Experiments and assessment of predictive methods. Int. J. Heat Mass Transf. 2018, 126, 1236-1552. [CrossRef]

7. Oh, H.K.; Ku, H.G.; Roh, G.S.; Son, C.H.; Park, S.J. Flow boiling heat transfer characteristics of carbon dioxide in a horizontal tube. Appl. Therm. Eng. 2008, 28, 1022-1030. [CrossRef]

8. Oh, H.K.; Son, C.H. Flow boiling heat transfer and pressure drop characteristics of $\mathrm{CO}_{2}$ in horizontal tube of 4.57-mm inner diameter. Appl. Therm. Eng. 2011, 31, 163-172. [CrossRef]

9. Lillo, G.; Mastrullo, R.; Mauro, A.W.; Viscito, L. Flow boiling of R32 in a horizontal stainless steel tube with $6.00 \mathrm{~mm}$ ID. Experiments, assessment of correlations and comparison with refrigerant R410A. Int. J. Refrig. 2019, 97, 143-156. [CrossRef]

10. Lillo, G.; Mastrullo, R.; Mauro, A.W.; Pelella, F.; Viscito, L. Experimental thermal and hydraulic characterization of R448A and comparison with R404A during flow boiling. Appl. Therm. Eng. 2019, 161, 114146. [CrossRef]

11. Citarella, B.; Lillo, G.; Mastrullo, R.; Mauro, A.W.; Viscito, L. Experimental investigation on flow boiling heat transfer and pressure drop of refrigerants R32 and R290 in a stainless steel horizontal tube. J. Phys. Conf. Ser. 2019, 1224, 01204. [CrossRef]

12. Jeong, S.; Park, D. Evaporative heat transfer of $\mathrm{CO} 2$ in a smooth and a micro-grooved miniature channel tube. Heat Transf. Eng. 2009, 30, 582-589. [CrossRef]

13. Viscito, L.; Lips, S.; Revellin, R. Global analysis and development of a predictive tool of the effect of tube inclination on two-phase heat transfer: Boiling, condensation and heated gas-liquid flows. Appl. Therm. Eng. 2019, 162, 114300. [CrossRef]

14. Wang, D.; Zhao, L.; Nie, X.; Lu, Y.; Deng, S. Experimental study on flow boiling characteristics of R-245fa in circular tube under non-uniform heat flux. Int. J. Heat Mass Transf. 2019, 143, 118570. [CrossRef]

15. Liu, T.; Pan, C. Infrared thermography measurement of two-phase boiling flow heat transfer in a microchannel. Appl. Therm. Eng. 2016, 94, 568-578. [CrossRef]

16. Jakubowska, B.; Mikielewicz, D.; Klugmann, M. Experimental study and comparison with predictive methods for flow boiling heat transfer coefficient of HFE7000. Int. J. Heat Mass Transf. 2019, 142, 118307. [CrossRef]

17. Cioncolini, A.; Thome, J.R. Liquid film circumferential asymmetry prediction in horizontal annular two-phase flow. Int. J. Multiph. Flow 2013, 51, 44-54. [CrossRef]

18. Mauro, A.W.; Cioncolini, A.; Thome, J.R.; Mastrullo, R. Asymetric annular flow in horizontal circular macro-channels: Basic modeling of liquid film distribution and heat transfer around the tube perimeter in convective boiling. Int. J. Heat Mass Transf. 2014, 77, 897-905. [CrossRef]

19. Mastrullo, R.; Mauro, A.W.; Viscito, L. Experimental CHF for low-GWP fluids and R134a. Effect of the Lh/D ratio at low and high mass velocities. Int. J. Heat Mass Trans. 2017, 109, 1200-1216. [CrossRef]

20. Mastrullo, R.; Mauro, A.W.; Thome, J.R.; Vanoli, G.P.; Viscito, L. Critical heat flux: Performance of R1234yf, R1234ze and R134a in an aluminum multi-minichannel heat sink at high saturation temperatures. Int. J. Therm. Sci. 2016, 106, 1-17. [CrossRef]

21. Fang, X.; Tang, D.; Zheng, L.; Li, G.; Yuan, Y. Experimental investigation of gravity and channel size effects on flow boiling heat transfer under hypergravity. Aerosp. Sci. Technol. 2019, 94, 105372. [CrossRef] 
22. Maqbool, M.H.; Palm, B.; Khodabandeh, R. Investigation of two phase heat transfer and pressure drop of propane in a vertical circular minichannel. Exp. Therm. Fluid Sc. 2013, 46, 120-130. [CrossRef]

23. Lillo, G.; Mastrullo, R.; Mauro, A.W.; Viscito, L. Flow boiling data of R452A. Energy Procedia 2018, 148, 1034-1041. [CrossRef]

24. Mastrullo, R.; Mauro, A.W.; Viscito, L. Flow boiling of R32 in a horizontal smooth tube of $6.0 \mathrm{~mm}$ internal diameter: Heat transfer coefficient and pressure drop. J. Phys. 2017, 923, 012015. [CrossRef]

25. Wojtan, L.; Ursenbacher, T.; Thome, J.R. Investigation of flow boiling in horizontal tubes: Part II-developement of a new heat transfer model for stratified-wavy, dryout and mist flow regimes. Int. J. Heat Mass Transf. 2005, 48, 2970-2985. [CrossRef]

26. Kondou, C.; Baba, D.; Mishima, F.; Koyama, S. Flow boiling of non-azeotropic mixture R32/R1234ze(E) in horizontal microfin tubes. Int. J. Refr. 2013, 36, 2366-2378. [CrossRef]

27. Azzolin, M.; Bortolin, S.; del Col, D. Flow boiling heat transfer of a zeotropic binary mixture of new refrigerants inside a single microchannel. Int. J. Therm. Sci. 2016, 110, 83-95. [CrossRef]

28. Charnay, R.; Revellin, R.; Bonjour, J. Flow boiling heat transfer in minichannels at high saturation temperatures: Part II-Assessment of predictive methods and impact of flow regimes. Int. J. Heat Mass Transf. 2015, 87, 653-672. [CrossRef]

29. Ali, R.; Palm, B. Dryout characteristics during flow boiling of R134a in vertical circular minichannels. Int. J. Heat Mass Transf. 2011, 54, 2434-2445. [CrossRef]

30. Leao, H.L.S.L.; Chàavez, C.A.; Nascimento, F.J.d.; Ribatski, G. An analysis of the effect of the footprint orientation on the thermal-hydraulic performance of a microchannel heat sink during flow boiling of R245fa. Appl. Therm. Engin. 2015, 90, 907-926. [CrossRef]

31. Lillo, G.; Mastrullo, R.; Mauro, A.W.; Viscito, L. Experimental study of flow boiling of propane in a $6 \mathrm{MM}$ internal diameter horizontal tube. Refrig. Sci. Technol. 2018, 2018, 798-806.

32. Lillo, G.; Mastrullo, R.; Mauro, A.W.; Viscito, L. Flow boiling of R1233zd(E) in a horizontal tube: Experiments, assessment and correlation for asymmetric annular flow. Int. J. Heat Mass Transf. 2019, 129, 547-561. [CrossRef]

33. Mastrullo, R.; Mauro, A.W.; Revellin, R.; Viscito, L. Flow boiling heat transfer and pressure drop of pure ethanol (99.8\%) in a horizontal stainless steel tube at low reduced pressures. Appl. Therm. Eng. 2018, 145, 251-263. [CrossRef]

34. Collier, J.G.; Thome, J.R. Convection Boiling and Condensation, 3rd ed.; McGraw-Hill: New York, NY, USA, 1994.

35. Grauso, S.; Mastrullo, R.; Mauro, A.W.; Vanoli, G.P. Flow boiling of R410A and $\mathrm{CO}_{2}$ from low to medium reduced pressures in macro channels: Experiments and assessment of prediction methods. Int. J. Heat Mass Transf. 2013, 56, 107-118. [CrossRef] 